\title{
Correlation of Heat and Cold Tolerance in Iranian Tall Fescue Ecotypes with Reactive Oxygen Species Scavenging and Osmotic Adjustment
}

\author{
Mohamad-Hossein Sheikh-Mohamadi ${ }^{1}$ and Nematollah Etemadi \\ Department of Horticulture, College of Agriculture, Isfahan University of \\ Technology, Isfahan 8415683111, Iran

Mostafa Arab
Department of Horticultural Sciences, College of Abouraihan, University of
Tehran, Tehran 3391653755, Iran

Additional index words. cold stress, diamine oxidase, Festuca arundinacea heat stress, polyamine oxidase, turfgrass

\begin{abstract}
Excessive heat or cold usually reduces the growth and quality of turfgrass. Genetic variations along with efficient biochemical and physiological mechanisms can diversify the tolerance to heat and cold. This study examined the effects of heat and cold stress on several biochemical and physiological parameters in Iranian tall fescue ecotypes (Festuca arundinacea L.). The control group of plants was maintained under optimal temperatures, whereas other groups were exposed to heat or cold in a growth chamber. The experiment was designed as a split plot, with stress treatments as the main plots and ecotypes as subplots. Physiologically and biochemically, the results revealed that three ecotypes ('FA1', 'FA3', and 'FA5') of the eight ecotypes examined in this study had better abilities to survive the simulated heat and cold stress. Better tolerance to heat and cold in the 'FA1', 'FA3', and 'FA5' ecotypes were probably due to higher levels of enzymatic and nonenzymatic antioxidant activities, maintenance of lower levels of malondialdehyde (MDA) and hydrogen peroxide $\left(\mathrm{H}_{2} \mathrm{O}_{2}\right)$, higher levels of proline and total nonstructural carbohydrates (TNC), along with a more efficient osmotic adjustment. Diamine oxidase (DAO) and polyamine oxidase (PAO) activities increased significantly in 'FA1', 'FA3', and 'FA5' ecotypes. In summary, the strength of tolerance among ecotypes can be ranked as 'FA1' $>$ 'FA3' $>$ 'FA5' $>$ 'FA2' $>$ 'FA6' $>$ 'FA4' $>$ 'FA7' $>$ 'FA8' under heat stress and 'FA5'> 'FA1' > 'FA3' > 'FA2' > 'FA4' > 'FA6' > 'FA7' > 'FA8' under cold stress.
\end{abstract}

Tall fescue (F. arundinacea $\mathrm{L}$.) is one of the main species of the Poaceae family. This cool-season grass has different characteristics including early maturity, drought tolerance, excellent seedling strength, and easy establishment. The tall fescue is commonly used for grassland rehabilitation on lighttextured soils in shrub lands and rangelands where precipitation is generally low (Pan et al., 2013).

Heat and cold stress are two major abiotic factors that limit plant growth and reduce the turf quality of cool-season grass by affecting several physiological and biochemical factors (Du et al., 2013; Fan et al., 2014). Heat and cold stress could lead to oxidative damages via the production of reactive oxygen species (ROS), such as superoxide anion $\left(\mathrm{O}_{2}^{-}\right)$and $\mathrm{H}_{2} \mathrm{O}_{2}$ (Meloni et al., 2003). Reactive oxygen species can seriously disrupt normal metabolism in plants via oxidative damages such as lipid peroxidation, protein degradation, and enzyme inactivation

Received for publication 23 Mar. 2018. Accepted for publication 18 May 2018.

${ }^{1}$ Corresponding author. E-mail:mh.sheikh@ag.iut. ac.ir.
(Etemadi et al., 2015). Different types of turfgrass have various mechanisms for their adaptation to heat and cold stress, including changes in physiological parameters and antioxidant defense systems ( $\mathrm{Yu}$ et al., 2012). Plants have evolved very efficient antioxidant defense systems to eradicate ROS during oxidative stress. This includes both enzymatic and nonenzymatic components, such as superoxide dismutase (SOD), Glutathione (GSH), catalase (CAT), peroxidase (POD), and ascorbate peroxidase (APX) (Sheikh-Mohamadi et al., 2018).

Turfgrass ecotypes exhibit different levels of tolerance to heat and cold. This has been evaluated by a number of researchers (Du et al., 2009; Jiang and Huang, 2001). Turfgrass ecotypes differ greatly in their ability to resist heat and cold stress. Evaluations of cultivars within a given group of species have been performed previously, although data on Iranian Tall fescue ecotypes are limited. In warm and cold climatic regions, selecting heat- and cold-tolerant species and ecotypes is a hopeful alternative to prevent heat- and cold-induced injuries, and such measures can be a benefit to turfgrass management (Soliman et al., 2012).
The identification of genetic variation and mechanisms that are involved in the tolerance to heat and cold can assist management programs for increasing turfgrass performance under heat and cold stress. Therefore, the present study aimed at evaluating Iranian tall fescue ecotypes along with their biochemical and physiological responses to heat and cold stress. Traits that may be associated with a greater ability to resist heat and cold have been considered.

\section{Materials and Methods}

Plant materials and growth conditions. Eight ecotypes of Iranian tall fescue $(F$. arundinacea L.) were used in this research. Seeds of tall fescue ecotypes were collected in Sept. 2016 from eight sites in Iran (Table 1). The collected seeds were planted in Oct. 2016 in the greenhouse. The seeds were germinated in polyvinyl chloride tubes (10 $\mathrm{cm}$ diameter and $40 \mathrm{~cm}$ length) filled with sterilized sandy loam soil. The water used for irrigation was characterized by a $\mathrm{pH}$ value of 7.2 and an electrical conductivity (EC) of $0.3 \mathrm{mS} \cdot \mathrm{cm}^{-1}$. The water was applied as needed to prevent any visible stress during the establishment phase of grass development. In general, grasses were watered three times weekly to maintain plants under wellwatered conditions. The soil moisture was maintained at field capacity and the grass was maintained at a cutting height of $5 \mathrm{~cm}$. The pots were then transferred to growth chambers where treatments were applied under natural light conditions (13-h photoperiod, relative humidity of $50 \%$ to $60 \%$, and photosynthetic photon flux density of $500 \mu \mathrm{mol} \cdot \mathrm{m}^{-2} \cdot \mathrm{s}^{-1}$ at the canopy level). The temperatures were set at $22^{\circ} \mathrm{C}$ day and $18^{\circ} \mathrm{C}$ night. Plants were allowed to acclimate to the conditions of the growth chamber for 2 weeks before the start of the experiment.

Treatments and experimental design. Iranian tall fescue ecotypes were subjected to the following three temperature treatments for $24 \mathrm{~d}$. The treatments were 1) optimal temperatures, 2) heat stress, and 3) cold stress. In the first group, plants were maintained at optimal temperature conditions of $22{ }^{\circ} \mathrm{C}$ day and $18{ }^{\circ} \mathrm{C}$ night; no heat or cold stress was applied. The second group had plants that were subjected to $35 / 30{ }^{\circ} \mathrm{C}$ (day/ night) (Abraham et al., 2008; Larkindale and Huang, 2004), and plants of the third group were subjected to $4{ }^{\circ} \mathrm{C}$ (day/night) (Fan et al., 2014). The plants were watered once a day to avoid water deficiency. The soil in the pots was kept humid $(60 \%$ to $80 \%$ of water holding capacity) throughout the experiment.

Physiological and biochemical measurements. Proline content, TNC content, MDA content, $\mathrm{H}_{2} \mathrm{O}_{2}$ content, DAO (EC 1.4.3.6), PAO (EC. 1.5.3.3), SOD (EC 1.15.1.1), APX (EC 1.11.1.11), POD (EC 1.111.1.7), CAT (EC 1.111.1.6) antioxidant enzymes activity, $\mathrm{GSH}$, and turf quality were measured on days $0,8,16$, and 24 , after the beginning of the heat and cold treatments. 
$\mathrm{H}_{2} \mathrm{O}_{2}$ content and MDA content analysis. Leaf samples $(0.5 \mathrm{~g})$ of the ecotypes were ground finely by using liquid nitrogen in icechilled mortar and pestle. They were homogenized in $10 \mathrm{~mL} \mathrm{10 \%} \mathrm{ice-cold} \mathrm{trichloroacetic}$ acid. The homogenate was then centrifuged at $20,000 g_{\mathrm{n}}$ for $25 \mathrm{~min}$ at $4{ }^{\circ} \mathrm{C}$. The supernatant was used to evaluate $\mathrm{H}_{2} \mathrm{O}_{2}$ content (Zhou et al., 2005) and MDA content (Heath and Parker, 1968).

Proline content, TNC content and GSH content analysis. Free proline content was determined by a spectrophotometer using the ninhydrin method according to Bates et al. (1973) with some modifications. Fresh leaves $(0.6 \mathrm{~g})$ were immersed in $6 \mathrm{~mL} \mathrm{5 \%}$ aqueous sulfosalicylic acid and were then centrifuged at $15,000 g_{\mathrm{n}}$ for $20 \mathrm{~min}$. The supernatant was treated with $1.6 \mathrm{~mL}$ of $3 \%$ acid ninhydrin dissolved in $1 \mathrm{~mL}$ of glacial acetic acid and was boiled for $1 \mathrm{~h}$. Absorbance was recorded at $520 \mathrm{~nm}$ with a calibration curve. The amount of TNC content was quantified according to the method of Fry et al. (1993) with some modifications and was expressed as $0.5 \mathrm{~g}$ of each sample (ecotype). Absorbance of the solution was read at $515 \mathrm{~nm}$ and was compared with a standard curve to determine the TNC content. GSH content was determined using the method of Griffith (1980) with slight modifications and was expressed as $0.6 \mathrm{~g}$ per ecotype samples. Absorbance was calculated at $412 \mathrm{~nm}$ and the GSH content was calculated by using the standard curve.

$D A O$ and PAO activities analysis. The activities of DAO and PAO were quantified by a modification of the radiometric method of Aribaud et al. (1994) and Faivre-Rampant et al. (2000). The ecotype samples (3 g) were homogenized in a prechilled mortar using $2 \mathrm{~mL}$ of $40 \mathrm{~mm}$ potassium phosphate buffer $(\mathrm{pH} 7.5)$. The homogenate was centrifuged at $18,000 g_{\mathrm{n}}$ for $30 \mathrm{~min}$ at $4{ }^{\circ} \mathrm{C}$. The supernatant was used to determine the activities of DAO and PAO. Changes in DAO and PAO activities were determined using the $\mathrm{H}_{2} \mathrm{O}_{2}$ /Ti method (Nag et al., 2000) after treatment with exogenously added polyamines, i.e., putrescine (Put), spermidine (Spd), and spermine (Spm).

Assay of antioxidant enzyme activities. Initially, $0.5 \mathrm{~g}$ of each ecotype sample was ground in $4 \mathrm{~mL}$ of $40 \mathrm{~mm}$ phosphate buffer $(\mathrm{pH} 7.4)$ at $6{ }^{\circ} \mathrm{C}$ that was then centrifuged at $16,000 g_{\mathrm{n}}$ for $20 \mathrm{~min}$. The supernatant was gathered for assays of antioxidant enzyme activities. Different antioxidant enzymes were extracted and the activities of APX, SOD, CAT, and POD were assessed by using the methods described by Chen et al. (2009) and Han et al. (2008).

Turf quality. Turf quality was visually rated on a 1-to-9 scale [National Turfgrass Evaluation Program (NTEP)] according to the turfgrass color, texture, density, and

Table 1. Geographical origin of Iranian tall fescue ecotypes.

\begin{tabular}{|c|c|c|c|c|c|c|c|}
\hline Code & Species & Region & Longitude (E) & Latitude $(\mathrm{N})$ & Altitude $(\mathrm{m})$ & Avg annual temp $\left({ }^{\circ} \mathrm{C}\right)$ & Annual rainfall $(\mathrm{mm} / \mathrm{yr})$ \\
\hline$\overline{\text { FA1 }}$ & Festuca arundinacea & Mobarakeh, Isfahan & $52.5132^{\circ} \mathrm{E}$ & $31.8427^{\circ} \mathrm{N}$ & 1,690 & 24.8 & 192.6 \\
\hline FA3 & & Darab, Shiraz & $54.3100^{\circ} \mathrm{E}$ & $28.5400^{\circ} \mathrm{N}$ & 1,180 & 20.4 & 176.2 \\
\hline FA4 & & Saveh, Markazi & $50.0136^{\circ} \mathrm{E}$ & $35.6980^{\circ} \mathrm{N}$ & 998 & 16.6 & 223.5 \\
\hline FA6 & & Arak, Markazi & $49.7013^{\circ} \mathrm{E}$ & $34.0954^{\circ} \mathrm{N}$ & 1,750 & 13.9 & 311 \\
\hline FA7 & & Aligudarz, Lorestan & $49.6962^{\circ} \mathrm{E}$ & $33.4050^{\circ} \mathrm{N}$ & 2,100 & 11.6 & 264.2 \\
\hline FA8 & & Takestan, Qazvin & $49.7013^{\circ} \mathrm{E}$ & $36.0721^{\circ} \mathrm{N}$ & 1,260 & 18.1 & 350 \\
\hline
\end{tabular}
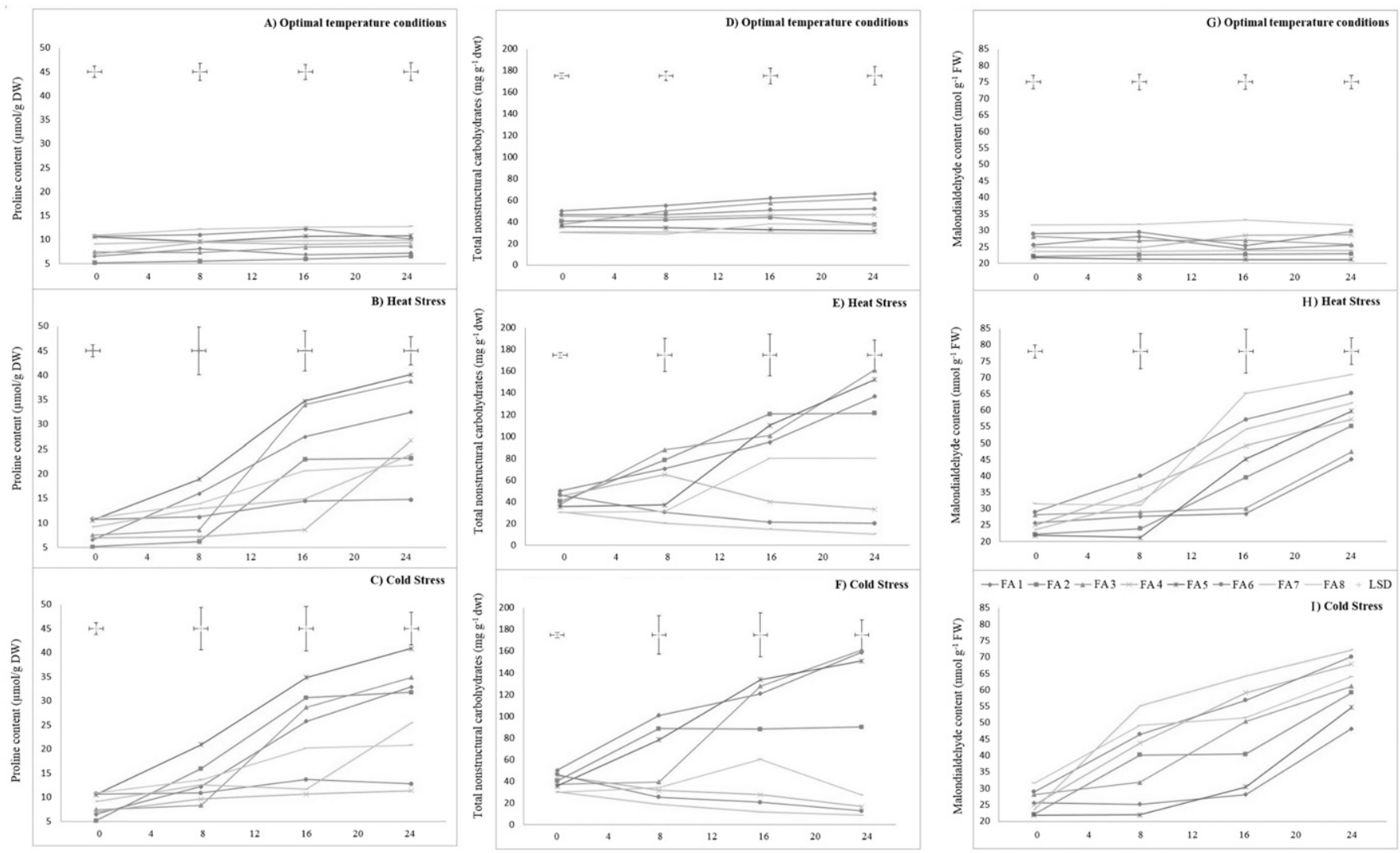

Fig. 1. Proline content, total nonstructural carbohydrates content, and malondialdehyde content of tall fescue ecotypes treated with (A, D, and G, respectively) optimal temperature conditions, (B, E, and $\mathbf{H}$, respectively) heat stress, and $(\mathbf{C}, \mathbf{F}$, and $\mathbf{I}$, respectively) cold stress. Least significant difference bars indicate significant differences between tall fescue ecotypes within a given day of treatment $(P=0.05)$. 
uniformity, where 1 represented a brown, absolutely dried necrotic turf covering. The value 6 represented an acceptable quality of turf, typical of a home lawn, and the value 9 meant optimum color, density, and uniformity (Beard, 1973).

Data analysis. The data were analyzed based on a split-plot design with the temperature treatments as main plots and ecotypes as subplots. Each stress and ecotype treatment had four replications. All pots were placed randomly in the growth chamber. The statistical significance was tested using the analysis of variance procedure in SAS 9.1 (SAS Institute Inc., Cary, NC). Differences between the mean values were determined using the Fisher's protected least significant difference test at the $5 \%$ probability level.

\section{Results and Discussion}

Heat and cold stress are considered to be major challenges as researchers consider climate change and the management of turfgrass (Du et al., 2013; Fan et al., 2014). Grass species and genotypes vary in their responses to heat and cold conditions. These responses include changes in the morphological, physiological, and biochemical mechanisms (Bocian et al., 2011; Yu et al., 2012). Understanding the mechanisms of grass tolerance to heat and cold stress is important in selecting grass species and genotypes to facilitate the breeding of varieties that can be more tolerant to heat and cold (Abraham et al., 2008; Bocian et al., 2011).

Plants have different mechanisms that help them cope with environmental stresses such as high and low temperatures, drought, and salinity (Liu et al., 2017). Osmotic adjustment is a mechanism for the maintenance of water potential in plant cells during periods of heat and cold stress (Zaher-Ara et al., 2016). Compatible cytosolutes including proline, TNC, soluble sugars and glycine betaine can reduce the cell's osmotic potential under dehydration (Sheikh-Mohamadi et al., 2017d). Proline is an important compatible osmolyte and a scavenger of ROS in plants (Akbari et al., 2018). During the experiment, proline content remained constant at optimal temperatures in all ecotypes (Fig. 1A). The proline content of 'FA1' and 'FA5' were higher than other ecotypes after 8,16 , and $24 \mathrm{~d}$ following the beginning of the heat and cold stress (Fig. 1B-C). Heat and cold stress increased the proline content in 'FA3' on days 16 and 24 (Fig. 1B-C). The increased accumulation of proline content in stressed plants may be an adaptation process and tolerance strategy to avoid abiotic stress in plants (Fan et al., 2014; Liu et al., 2011). Sarmast et al. (2015) found significant variability in proline content among different ecotypes when comparing the proline content among different tall fescue ecotypes under abiotic stress conditions. Furthermore, it is believed that proline protects plants against stress by different means such as the contribution toward osmotic adjustment, membrane integrity, detoxification of ROS, and the native structures of enzymes and proteins (Bocian et al., 2011; Liu et al., 2017).

The TNC content in plants contains fructans, starch, and water-soluble carbohydrates. Numerous studies have demonstrated that the TNC content increases during heat and cold stress, and TNC accumulation is associated with improvement in the tolerance to heat and cold, for example, in the creeping bentgrass and other plants (Liu and Huang, 2000; Sheikh-Mohamadi et al., 2018). The results of this study also revealed that the control plants of all ecotypes (situated at optimal temperatures) showed a stable TNC content throughout the duration of the study, and no significant differences were observed between the ecotypes (Fig. 1D). On all days of the experiment, the TNC content increased in 'FA1' and 'FA3' under heat stress. The same was observed in 'FA1' and 'FA5' under cold stress (Fig. 1E-F). The TNC content decreased in 'FA6' and 'FA7' under heat stress and it decreased in 'FA4', 'FA6', and 'FA7' under cold stress after 8, 16 and $24 \mathrm{~d}$ of the temperature treatments (Fig. 1E-F). Huang and Gao (2000) reported that tolerant cultivars of tall fescue accumulate more TNC
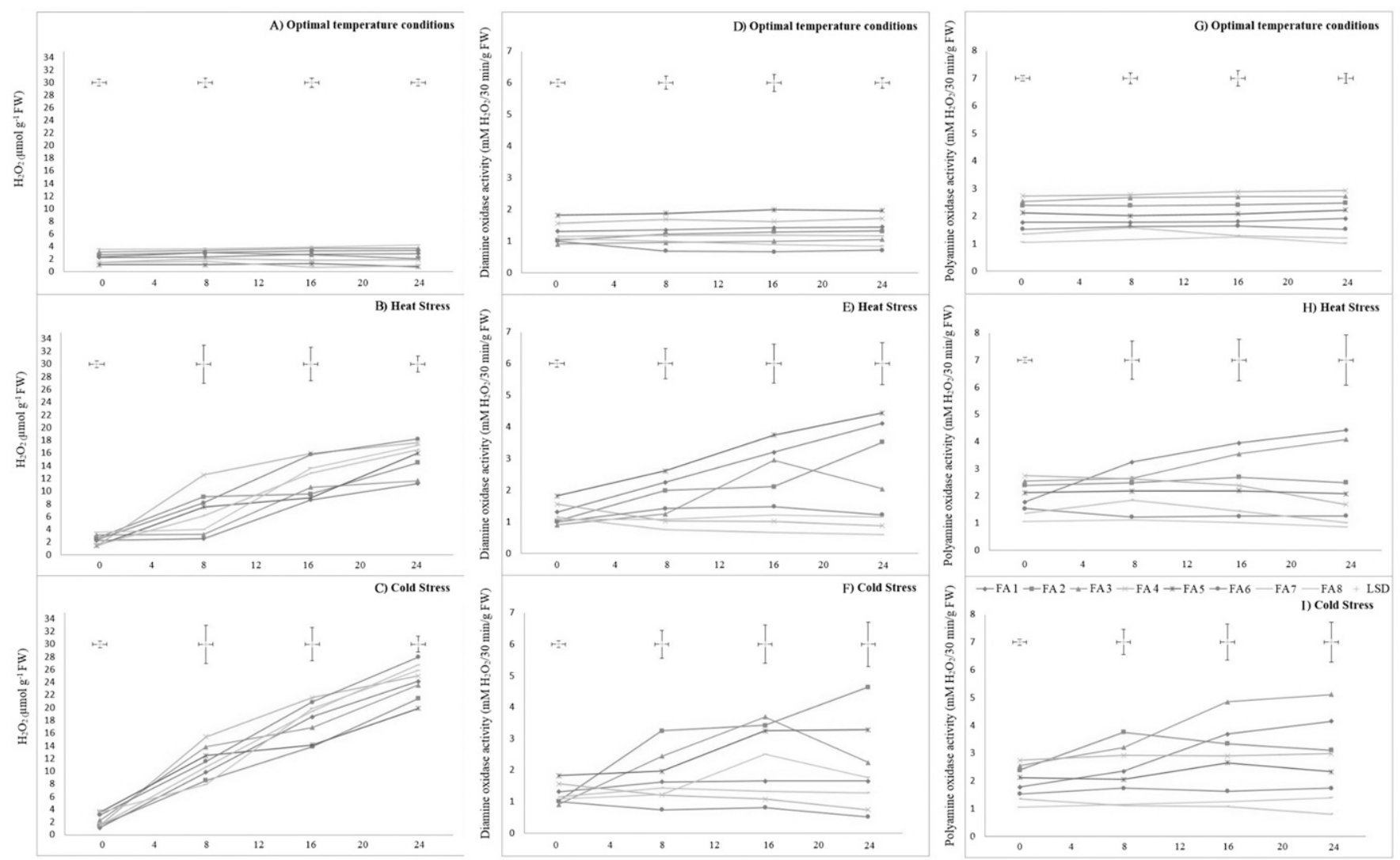

Fig. 2. $\mathrm{H}_{2} \mathrm{O}_{2}$ content, diamine oxidase activity, and polyamine oxidase activity of tall fescue ecotypes treated with (A, D, and $\mathbf{G}$, respectively) optimal temperature conditions, (B, E, and $\mathbf{H}$, respectively) heat stress, and $(\mathbf{C}, \mathbf{F}$, and $\mathbf{I}$, respectively) cold stress. Least significant difference bars indicate significant differences between tall fescue ecotypes within a given day of treatment $(P=0.05)$. 
Malondialdehyde is one of the final products of chemical degradation during the peroxidation of lipids in the cell membrane. Damages to the cell membrane can be caused by free radicals under abiotic stress, and MDA is described as an indicator of the extent to which a plant is damaged (Han et al., 2014). It has commonly been applied to differentiate between heat- and cold-tolerant species and also to distinguish between heatand cold-susceptible species and ecotypes (Du et al., 2009, 2013). After 8 and 16 d of temperature treatments, there was no change in the MDA content of 'FA1' and 'FA3' under heat and also no changes in 'FA1' and 'FA5' under cold stress (Fig. 1H-I). At the end of the experiment ( $24 \mathrm{~d}$ following the beginning of the temperature treatments), the MDA content increased in 'FA1' and 'FA3' under heat stress. It also increased in 'FA1' and 'FA5' under cold stress (Fig. 1HI). A lower MDA content has been associated with a better tolerance to environmental stress among plants (Filek et al., 2012).

Stressful conditions encourage plants to overproduce ROS, such as $\mathrm{H}_{2} \mathrm{O}_{2}$, which may result in serious damages to vital cellular organelles (Sheikh-Mohammadi et al., 2017a). For instance, $\mathrm{H}_{2} \mathrm{O}_{2}$ can damage DNA, enzymes, proteins, chlorophyll, membrane lipids, pigments, and nucleic acids (Ben Amor et al., 2006; Xu et al., 2013). The $\mathrm{H}_{2} \mathrm{O}_{2}$ content in all ecotypes increased under heat and cold stress, compared with the control (Fig. 2B-C). After 16 and $24 \mathrm{~d}$ of the temperature treatments, the $\mathrm{H}_{2} \mathrm{O}_{2}$ content increased in 'FA1' and 'FA3' under heat stress. Similarly, the content increased in 'FA2' under cold stress (Fig. 2B-C). Heat and cold stress increased the $\mathrm{H}_{2} \mathrm{O}_{2}$ content in 'FA4', 'FA7', and 'FA8' within 8, 16, and $24 \mathrm{~d}$ of the temperature treatments (Fig. 2BC). After 8 and $24 \mathrm{~d}$ of the experiment, the $\mathrm{H}_{2} \mathrm{O}_{2}$ content increased in 'FA2' and ' $\mathrm{FA}$ 5' under heat stress. Similar increases were observed in 'FA1', 'FA3', and 'FA5' under cold stress (Fig. 2B-C). Low levels of $\mathrm{H}_{2} \mathrm{O}_{2}$ have been associated with better tolerance to heat and cold stress (Soliman et al., 2012).

In plants, important roles of DAO and PAO activities occur in a wide range of biochemical and physiological processes that have been reported in germination, defense responses against abiotic stress (e.g., drought, cold, salinity, and high temperature stress) and biotic stress (e.g., bacteria, viruses, fungi, and parasites), flowering and senescence (An et al., 2008; Moschou et al., 2008). It is believed that DAO and PAO play important roles in the production of $\mathrm{H}_{2} \mathrm{O}_{2}$ through the catabolism of polyamines in plant tissues (Alcázar et al., 2010; Xing et al., 2007). DAO is the main enzyme that catalyzes the oxidative deamination of diamines. DAO catalyzes the oxidative deamination of diamines to putrescine and subsequently into pyrroline, ammonia, and $\mathrm{H}_{2} \mathrm{O}_{2}$ (Alcázar et al., 2011). In this study, after 8,16 , and $24 \mathrm{~d}$ of temperature treatments, the activity of DAO enzymes increased in 'FA1' and 'FA5' during heat stress (Fig. 2E). The DAO enzyme activity increased in 'FA2' under heat and cold stress on days 8 and 24 of the temperature treatments (Fig. 2E-F). After $16 \mathrm{~d}$ of the temperature treatments, the DAO activity increased in 'FA3' under heat stress and in 'FA8' during cold stress but then it decreased (Fig. 2E-F). After 8 and $16 \mathrm{~d}$ of the experiment, the DAO enzyme activity increased in 'FA3' under cold stress and then decreased (Fig. 3F). PAO is involved in the catabolism of polyamines and acetyl polyamines. Polyamines are essential factors for growth and survival. PAO is a very important enzyme that regulates the polyamine metabolic pathway (biosynthesis, catabolism, and regulation) in different plant systems (Sánchez-Rodríguez et al., 2016). PAO activities occur frequently in the cell walls of grass, and they constitute the terminal catabolism of polyamines and the production of $\mathrm{H}_{2} \mathrm{O}_{2}$ (Alcázar et al., 2011). After 8, 16, and $24 \mathrm{~d}$ of the temperature treatments, the PAO activity increased in 'FA1' and 'FA3' because of the heat and cold stress (Fig. 2H-I). The PAO enzyme activity increased in ' $F A 7$ ' under heat stress. The activity also increased in 'FA2' during cold stress after $8 \mathrm{~d}$ of the temperature treatments but then showed
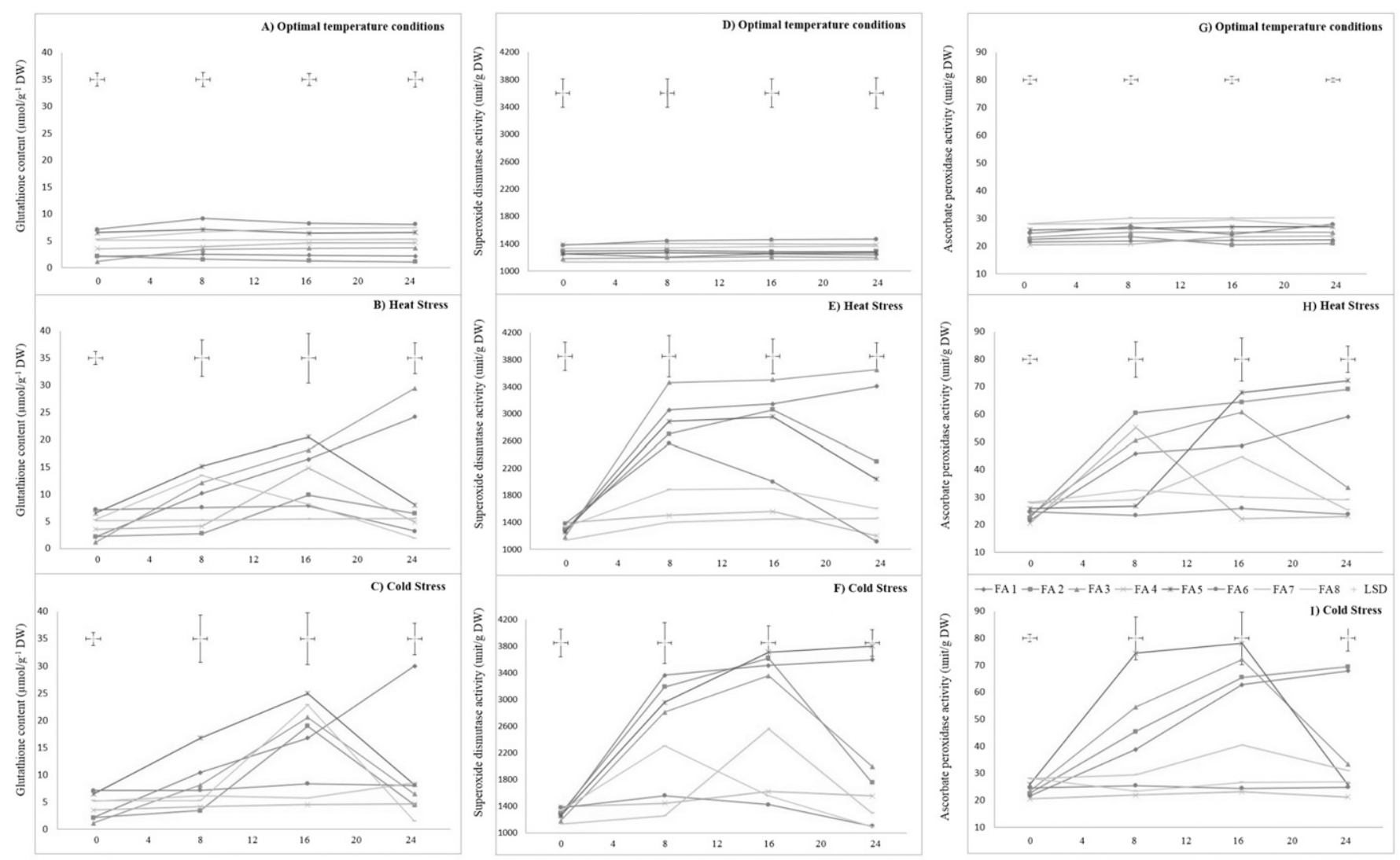

Fig. 3. Glutathione content, superoxide dismutase activity, and ascorbate peroxidase activity of tall fescue ecotypes treated with (A, D, and G, respectively) optimal temperature conditions, (B, E, and $\mathbf{H}$, respectively) heat stress, and $(\mathbf{C}, \mathbf{F}$, and $\mathbf{I}$, respectively) cold stress. Least significant difference bars indicate significant differences between tall fescue ecotypes within a given day of treatment $(P=0.05)$. 
a downward trend (Fig. 2H-I). After $16 \mathrm{~d}$ of the temperature treatments, the activity of PAO enzyme increased in 'FA5' during cold stress but then decreased (Fig. 3I). Cvikrová et al. (2012), Sánchez-Rodríguez et al. (2016) and Toumi et al. (2010) observed a rapid and continued increase in DAO and PAO activities in cultivars tolerant to abiotic stress. Improved activities of DAO and PAO activities can develop plant tolerance. They have also been reported in several higher plants and during their tolerance to environmental stress (Shoresh et al., 2011; Tang and Newton, 2005). Researchers found that activities of DAO and PAO enzymes produce $\mathrm{H}_{2} \mathrm{O}_{2}$ in response to environmental and biotic stress. The product may generate mediated signals in the structural defense system by signal molecules or by an induced antioxidant response (Tang and Newton, 2005).

Plants have antioxidant defense systems to protect them against the deleterious effects of ROS, such as $\mathrm{H}_{2} \mathrm{O}_{2}$, which are produced at high levels when plants are exposed to abiotic stress conditions (Sheikh-Mohammadi et al., 2017a). The antioxidant defense system consists of several antioxidant enzymes such as SOD, CAT, APX, POD, and some nonenzymatic antioxidants such as GSH, which are capable of eliminating $\mathrm{H}_{2} \mathrm{O}_{2}$, neutralizing or scavenging free radicals (Sheikh-Mohamadi et al., 2017b). GSH plays a defensive role in the scavenging of singlet oxygen, hydroxyl radicals, and peroxides (Guo et al., 2006). Lu et al. (2008) reported that a higher content of GSH under environmental stress is associated with increased stress tolerance in the bermudagrass. On all days of the experiment, the GSH content increased in 'FA1' and 'FA3' under heat stress and also increased in 'FA1' under cold stress (Fig. 3B-C). The GSH content increased in 'FA5' during heat stress and also in 'FA3' and 'FA5' during cold stress, after 8 and $24 \mathrm{~d}$ of the temperature treatments (Fig. 3B-C). SOD is a key antioxidant enzyme that catalyzes the conversion of superoxide radicals to $\mathrm{H}_{2} \mathrm{O}_{2}$ and molecular oxygen (Sheikh-Mohamadi et al., 2017c). SOD enzyme activity in 'FA1', 'FA3', and 'FA5' were higher than in other grasses under heat and cold conditions (Fig. 3E-F). After 8, 16 , and $24 \mathrm{~d}$ of the temperature treatments, the activity of SOD increased in 'FA1' and 'FA3' under heat stress and in 'FA1' and 'FA5' under cold stress (Fig. 3E-F). After $16 \mathrm{~d}$ of the temperature treatments, the activity of the SOD enzyme increased in 'FA2', 'FA3', and 'FA7' during cold stress and then the activity decreased (Fig. 3C). In enzymatic antioxidant systems, APX and POD are essential enzymes in the cyclic activities of plants. APX and POD are necessary to transform $\mathrm{H}_{2} \mathrm{O}_{2}$ to $\mathrm{H}_{2} \mathrm{O}$ and $\mathrm{O}_{2}$ within the GSH-ascorbate cycle in chloroplasts (Sheikh-Mohamadi et al., 2017c). After 8,16 , and $24 \mathrm{~d}$ of the temperature treatments, the activity of APX increased in 'FA1' and 'FA2' under heat and cold stress (Fig. 3H-I). After 8 and $16 \mathrm{~d}$ of the temperature treatments, the APX activity increased in 'FA3' under heat stress and in 'FA3' and 'FA5' under cold stress and then the activity decreased (Fig. 3H-I). Heat stress increased the activity of APX enzymes in 'FA5' after 16 and $24 \mathrm{~d}$ of the temperature treatments (Fig. 3H). On all days of the experiment, the activity of POD enzyme increased in 'FA1', 'FA3', and 'FA5' under heat stress. It also increased in 'FA1' and 'FA2' under cold stress (Fig. 4B-C). During the first $16 \mathrm{~d}$ of the temperature treatments, the POD activity increased in 'FA2' under heat stress and in 'FA5' under cold stress, and then the activity decreased (Fig. 4B-C). CAT is able to turn $\mathrm{H}_{2} \mathrm{O}_{2}$ to $\mathrm{H}_{2} \mathrm{O}$ and $\mathrm{O}_{2}$ which is followed by the removal of this radical oxygen species. CAT controls paroxysmal $\mathrm{H}_{2} \mathrm{O}_{2}$ without limiting its production (Hosseini et al., 2010). CAT activity increased in 'FA3' and 'FA5' under heat stress and in 'FA1' under cold stress within 8,16 , and $24 \mathrm{~d}$ of the treatment (Fig. 4E-F). In 'FA4', 'FA6', and 'FA7', the CAT activity remained constant under both heat and cold stress (Fig. 4E-F). After 8 and $16 \mathrm{~d}$ of the temperature treatments, the CAT activity increased in 'FA1' and 'FA2' under heat stress and in 'FA2', 'FA3', and 'FA5' under cold stress and then the activity decreased (Fig. 4E-F). According to the
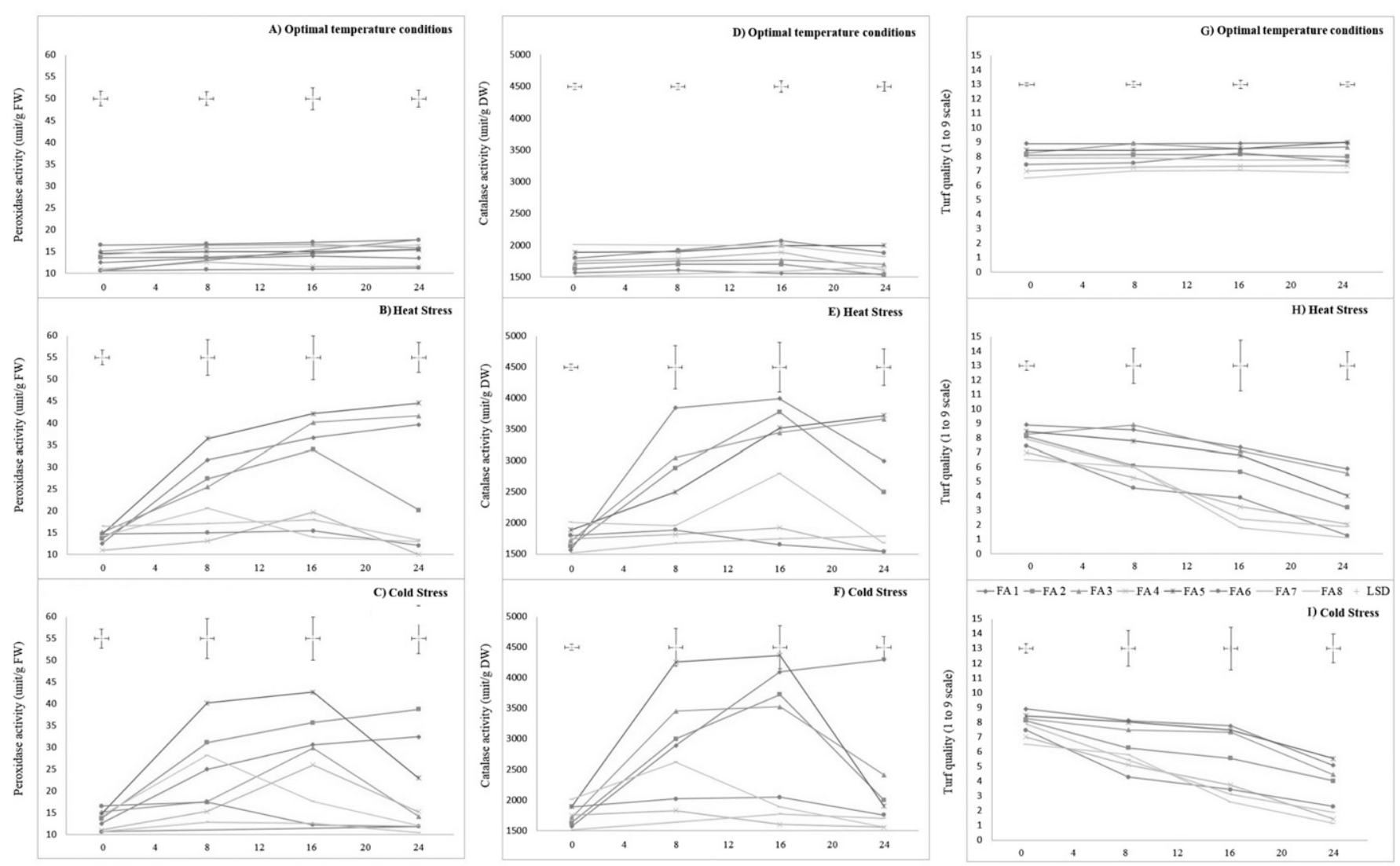

Fig. 4. Peroxidase activity, catalase activity, and turf quality of tall fescue ecotypes treated with (A, D, and $\mathbf{G}$, respectively) optimal temperature conditions, (B, E, and $\mathbf{H}$, respectively) heat stress, and $(\mathbf{C}, \mathbf{F}$, and $\mathbf{I}$, respectively) cold stress. Least significant difference bars indicate significant differences between tall fescue ecotypes within a given day of treatment $(P=0.05)$. 
results of this study, tolerant ecotypes exhibited higher activities of antioxidant enzymes than heat- and cold-sensitive ecotypes. Maintaining a high level of antioxidative enzyme activities may contribute to heat and cold tolerance by improving the protective mechanisms against oxidative stress damages (Du et al., 2013; Fan et al., 2014; He and Huang, 2010; Liu et al., 2017). On the other hand, a decrease was observed in antioxidant enzyme activities including SOD, CAT, APX, and POD in some tall fescue ecotypes during prolonged heat and cold stress ( $24 \mathrm{~d})$. This was probably because of the toxic effect of the overproduction of $\mathrm{O}_{2}$ and $\mathrm{H}_{2} \mathrm{O}_{2}$ or its poisonous ROS derivatives, as observed by the higher $\mathrm{H}_{2} \mathrm{O}_{2}$ and MDA accumulation in the leaves of the tolerant ecotypes (Fan et al., 2014; Soliman et al., 2012). Higher activities of antioxidant enzymes have been reported in heat-tolerant tall fescue ecotypes (Cui et al., 2006). According to previous research, changes in the activities of antioxidant enzymes under heat and cold stress depend on plant species, ecotypes, the length, and intensity of the stress (Du et al., 2009; Espevig et al., 2012).

In turfgrass research, turf quality is investigated to evaluate the effects of environmental stress in grass species and ecotypes. In our experiment, under heat and cold stress, the turf quality of all ecotypes demonstrated a steady decline, and the rate of decline was different between ecotypes (Fig. 4G). 'FA1' and 'FA3' under heat stress and 'FA1' and 'FA5' under cold stress had significantly higher turf quality than other ecotypes during the experiment and maintained acceptable turf quality ( 7.0 or higher) within the first $16 \mathrm{~d}$ following temperature treatments (Fig. 4H-I). After 8, 16 and $24 \mathrm{~d}$ of the temperature treatments, turf quality decreased in 'FA4', 'FA6', and 'FA7' under heat and cold stress (Fig. 4H-I). By the end of the exposure to temperature stress $(24 \mathrm{~d}$ following temperature treatments), turf quality of all ecotypes decreased to a level below the acceptable turf quality (Fig. 4H-I). Grass species and ecotypes that can maintain high levels of turf quality for a longer period of time under heat and cold stress are indicative of the higher tolerance to heat and cold stress (Du et al., 2009; Ebdon et al., 2002; Yu et al., 2012).

\section{Conclusions}

In summary, the results of this study indicate genetic variation in heat and cold tolerance in tall fescue ecotypes. Turf quality of all ecotypes decreased to improper quality rankings at the end of the experiment. In fact, turf quality declined with increasing heat and cold stress. Nevertheless, this decline in the turf visual quality was less severe for ecotypes 'FA1', 'FA3', and 'FA5' that had greater turf quality than other ecotypes under stress conditions. 'FA7' and 'FA8' had the poorest quality among all ecotypes. Based on biochemical and physiological analysis of heat and cold tolerance, the diversity of heat and cold tolerance among Iranian tall fescue ecotypes was substantial. 'FA1' and 'FA3' were heat tolerant; 'FA5' and 'FA2' were moderately heat tolerant; and 'FA4', 'FA6', 'FA7', 'Regent', and 'FA8' were heat sensitive. Moreover, 'FA1', 'FA5', and 'FA3' were cold tolerant, 'FA2' was moderately cold tolerant, and 'FA6', 'FA7', 'FA4', and 'FA8' were cold-sensitive. The MDA content in 'FA1', 'FA3', and 'FA5' was significantly lower than in other ecotypes under heat and cold stress, indicating that less lipid peroxidation occurred as a result of higher antioxidant enzyme activities. Moreover, a lower $\mathrm{H}_{2} \mathrm{O}_{2}$ content was observed in 'FA1', 'FA3', and 'FA5'. The data demonstrated that superior heat and cold tolerance in 'FA1', 'FA3', and 'FA5' could be characterized by the higher activities of enzymatic antioxidants and nonenzymatic antioxidants; higher proline and TNC content; lower MDA and $\mathrm{H}_{2} \mathrm{O}_{2}$ contents; and higher activities of DAO and PAO. The results suggest that the selection and use of ecotypes with higher activities of enzymatic antioxidants (SOD, POD, CAT, and APX), nonenzymatic antioxidants (GHS), DAO, and PAO may improve the quality of tall fescue ecotypes under heat and cold stress. Finally, according to the results, it may be suggested that 'FA1' and 'FA3' are the strongest ecotypes in tolerance to heat and that the 'FA1' and 'FA5' are the strongest ecotypes in tolerance to cold stress. These ecotypes would be advised for future cultivation under conditions that are usually characterized by excessive heat or cold.

\section{Literature Cited}

Abraham, E.M., W.A. Meyer, S.A. Bonos, and B. Huang. 2008. Differential responses of hybrid bluegrass and Kentucky bluegrass to drought and heat stress. HortScience 43:2191-2195.

Akbari, M., N. Mahna, K. Ramesh, A. Bandehagh, and S. Mazzuca. 2018. Ion homeostasis, osmoregulation, and physiological changes in the roots and leaves of pistachio rootstocks in response to salinity. Protoplasma, doi: 10.1007/ s00709-018-1235-z.

Alcázar, R., T. Altabella, F. Marco, C. Bortolotti, M. Reymond, C. Koncz, P. Carrasco, and A.F. Tiburcio. 2010. Polyamines: Molecules with regulatory functions in plant abiotic stress tolerance. Planta 231:1237-1249.

Alcázar, R., M. Bitrián, D. Bartels, C. Koncz, T. Altabella, and A.F. Tiburcio. 2011. Polyamine metabolic canalization in response to drought stress in Arabidopsis and the resurrection plant Craterostigma plantagineum. Plant Signal. Behav. 6:243-250.

An, Z., W. Jing, Y. Liu, and W. Zhang. 2008. Hydrogen peroxide generated by copper amine oxidase is involved in abscisic acid-induced stomatal closure in Vicia faba. J. Expt. Bot. 59:815-825.

Aribaud, M., M. Carre, and J. Martin-Tanguy. 1994. Polyamine metabolism and in-vitro cell multiplication and differentiation in leaf explants of Chrysanthemum morifolium Ramat. Plant Growth Regulat. 15:143-155.

Bates, L.S., R.P. Waldren, and I.D. Teare. 1973. Rapid determination of free proline for water stress studies. Plant Soil 39:205-207.

Beard, J.B. 1973. Turfgrass: Science and culture. Prentice-Hall, Inc., Englewood Cliffs, NJ.
Ben Amor, N., A. Jiménez, W. Megdiche, M Lundqvist, F. Sevilla, and C. Abdelly. 2006. Response of antioxidant systems to $\mathrm{NaCl}$ stress in the halophyte Cakile maritima. Physiol. Plant. 126:446-457.

Bocian, A., A. Kosmalaa, M. Rapacz, B. Jurczyk, and L. Marczak. 2011. Differences in leaf proteome response to cold acclimation between Lolium perenne plants with distinct levels of frost tolerance. J. Plant Physiol. 168:1271-1279.

Chen, C., S. Lu, Y. Chen, Z. Wang, Y. Niu, and Z. Guo. 2009. A gamma-ray induced dwarf mutant from seeded Bermuda grass and its physiological responses to drought stress. HortScience 134:22-30.

Cui, L., J. Li, Y. Fan, S. Xu, and Z. Zhang. 2006. High temperature effects on photosynthesis, PSII functionality and antioxidant activity of two Festuca arundinacea genotypes with different heat susceptibility. Bot. Stud. 47:61-69.

Cvikrová, M., L. Gemperlová, J. Dobrá, O. Martincová, I.T. Prásil, J. Gubis, and R. Vanková. 2012. Effect of heat stress on polyamine metabolism in proline-over-producing tobacco plants. Plant Sci. 182:49-58.

Du, H., Z. Wang, and B. Huang. 2009. Differential responses of warm-season and cool season turfgrass species to heat stress associated with antioxidant enzyme activity. J. Amer. Soc. Hort. Sci. 134:417-422.

Du, H., P. Zhou, and B. Huang. 2013. Antioxidant enzymatic activities and gene expression associated with heat tolerance in a cool-season perennial grass species. Environ. Expt. Bot. 87:159-166.

Ebdon, J.S., R.A. Gagne, and R.A. Manley. 2002. Comparative cold tolerance in diverse turf quality genotypes of perennial ryegrass. HortScience 37:826-830.

Espevig, T., C. Xu, T.S. Aamlid, M. DaCosta, and B. Huang. 2012. Proteomic responses during cold acclimation in association with freezing tolerance of velvet bentgrass. J. Amer. Soc. Hort. Sci. 137:391-399.

Etemadi, N., M.H. Sheikh-Mohammadi, A. Nikbakht, M.R. Sabzalian, and M. Pessarakli. 2015. Influence of trinexapac-ethyl in improving drought resistance of wheatgrass and tall fescue. Acta Physiol. Plant. 53:1-17.

Faivre-Rampant, O., C. Kevers, J. Dommes, and T. Gaspar. 2000. The recalcitrance to rooting of micro propagated shoots of the rac tobacco mutant: Implication of polyamines and the polyamine metabolism. Plant Physiol. Biochem. 38:441-448.

Fan, J., J. Ren, W. Zhu, E. Amombo, J. Fu, and L. Chen. 2014. Antioxidant responses and gene expression in s under cold stress. J. Amer. Soc. Hort. Sci. 139:699-705.

Filek, M., S. Walas, H. Mrowiec, E. RudolphySko'rska, A. Sieprawska, and J. BiesagaKos'cielniak. 2012. Membrane permeability and micro- and macro-element accumulation in spring wheat cultivars during the short-term effect of salinity- and PEG-induced water stress. Acta Physiol. Plant. 34:985-995.

Fry, J.D., S.N. Lang, R. Clifton, and F.P. Maier. 1993. Freezing tolerance and carbohydrate content of low temperature-acclimated and non-acclimated centipede grass. Crop Sci. 33:1051-1055.

Griffith, O.W. 1980. Determination of glutathione and glutathione disulfide using glutathione reductase and 2-vinylpyridine. Anal. Biochem. 106:207-212.

Guo, Z., W. Ou, S. Lu, and Q. Zhong. 2006. Differential responses of antioxidative system to chilling and drought in four rice cultivars 
differing in sensitivity. Plant Physiol. Biochem. 44:828-836.

Han, H.M., L. Bai, J.J. Su, J.P. Zhang, L.Q. Song, A.N. Gao, X.M. Yang, X.Q. Li, W.H. Liu, and L.H. Li. 2014. Genetic rearrangements of six wheat-Agropyron cristatum 6P addition lines revealed by molecular markers. PLoS One 9: E91066.

Han, L.B., G.L. Song, and X. Zhang. 2008. Preliminary observation of physiological responses of three turfgrass species to traffic stress. HortTechnology 18:139-143.

He, Y. and B. Huang. 2010. Differential responses to heat stress in activities and isozymes of four antioxidant enzymes for two genotypes of Kentucky bluegrass contrasting in heat tolerance. J. Amer. Soc. Hort. Sci. 135:116-124.

Heath, R.L. and L. Parker. 1968. Photoperoxidation in isolated chloroplasts: I. Kinetics and stiochiometry of fatty acid peroxidation. Arch. Biochem. Biophys. 125:189-198.

Hosseini, T., F. Shekari, and M. Ghorbanli. 2010. Effect of salt stress on ion content, proline and antioxidative enzymes of two safflower cultivars (Carthamus tinctorius L.). J. Food Agr. Environ. 8:1080-1086.

Huang, B. and H. Gao. 2000. Root physiological characteristics associated with drought resistance in tall fescue cultivars. Crop Sci. 40:196203.

Jiang, Y. and B. Huang. 2001. Drought and heat stress injury to two cool-season turfgrasses in relation to antioxidant metabolism and lipid peroxidation. Crop Sci. 41:436-442.

Larkindale, J. and B. Huang. 2004. Thermo tolerance and antioxidant systems in Agrostis stolonifera: Involvement of salicylic acid, abscisic acid, calcium, hydrogen peroxide, and ethylene. J. Plant Physiol. 161:405-413.

Liu, C., Y. Liu, K. Guo, D. Fan, G. Li, and Y. Zheng. 2011. Effect of drought on pigments, osmotic adjustment and antioxidant enzymes in six woody plant species in karst habitats of southwestern China. Environ. Expt. Bot. 71:174-183.

Liu, X. and B. Huang. 2000. Heat stress injury in relation to membrane lipid peroxidation in creeping bentgrass. Crop Sci. 40:503-510.

Liu, Z., P. Liu, D. Qi, X. Peng, and G. Liu. 2017. Enhancement of cold and salt tolerance of Arabidopsis by transgenic expression of the S-adenosylmethionine decarboxylase gene from Leymus chinensis. J. Plant Physiol. 211:90-99.
Lu, S., Z. Wang, Y. Niu, Z. Guo, and B. Huang. 2008. Antioxidant responses of radiation-induced dwarf mutants of Bermudagrass to drought stress. J. Amer. Soc. Hort. Sci. 133:360-366.

Meloni, D.A., M.A. Oliva, C.A. Martinez, and J. Cambraia. 2003. Photosynthesis and activity of superoxide dismutase, peroxidase and glutathione reductase in cotton under salt stress. Environ. Expt. Bot. 49:69-76.

Moschou, P.N., I.D. Delis, K.A. Paschalidis, and K.A. Roubelakis-Angelakis. 2008. Transgenic tobacco plants overexpressing polyamine oxidase are not able to cope with oxidative burst generated by abiotic factors. Physiol. Plant. 133:140-156.

Nag, K., R.R. Harbottle, and A.K. Pand. 2000. Molecular architecture of a self-assembled biointerface: Lung surfactant. J. Surface Sci. Technol. 16:157-170.

Pan, X., J.Q. Moss, Y. Wu, N.O. Maness, and K. Su. 2013. Tall fescue performance and protein alteration during drought stress. Intl. Turfgrass Soc. Res. J. 12:465-473.

Sánchez-Rodríguez, E., L. Romero, and J.M. Ruiz. 2016. Accumulation of free polyamines enhances the antioxidant response in fruits of grafted tomato plants under water stress. J. Plant Physiol. 190:72-78.

Sarmast, M.K., H. Salehi, and A. Niazi. 2015. Biochemical differences underlie varying drought tolerance in four Festuca arundinacea Schreb. Genotypes subjected to short water scarcity. Acta Physiol. Plant. 37:192.

Sheikh-Mohammadi, M.H., N. Etemadi, M. Arab, M. Aalifar, M. Arab, and M. Pessarakli. 2017a. Molecular and physiological responses of Iranian Perennial ryegrass as affected by Trinexapac ethyl, Paclobutrazol and Abscisic acid under drought stress. Plant Physiol. Biochem. 111:129-143.

Sheikh-Mohamadi, M.H., N. Etemadi, and A. Nikbakht. 2017b. Physiological responses of two coolseason grass species to trinexapac-ethyl under traffic stress. HortScience 52:99-109.

Sheikh-Mohamadi, M.H., N. Etemadi, A. Nikbakht, M. Arab, and M.M. Majidi. 2017c. Antioxidant defence system and physiological responses of Iranian crested wheatgrass (Agropyron cristatum L.) to drought and salinity stress. Acta Physiol. Plant. 39:245.

Sheikh-Mohamadi, M.H., N. Etemadi, A. Nikbakht, M. Farajpour, M. Arab, and M.M. Majidi. 2017d. Screening and selection of twenty Iranian wheatgrass genotypes for tolerance to salinity stress during seed germination and seedling growth stage. HortScience 52:11251134.

Sheikh-Mohamadi, M.H., N. Etemadi, A. Nikbakht, M. Farajpour, M. Arab, and M.M. Majidi. 2018. Wheatgrass germination and seedling growth under osmotic stress. Agron. J. 110:1-14.

Shoresh, M., M. Spivak, and N. Bernstein. 2011. Involvement of calcium-mediated effects on ROS metabolism in the regulation of growth improvement under salinity. Free Radic. Biol. Med. 51:1221-1234.

Soliman, W.S., M. Fujimori, K. Tase, and S. Sugiyama. 2012. Heat tolerance and suppression of oxidative stress: Comparative analysis of 25 cultivars of the $\mathrm{C} 3$ grass Lolium perenne. Environ. Expt. Bot. 78:10-17.

Tang, W. and R.J. Newton. 2005. Polyamines reduce salt-induced oxidative damage by increasing the activities of antioxidant enzymes and decreasing lipid peroxidation in Virginia pine. Plant Growth Regulat. 46:31-43.

Toumi, I., P.N. Moschou, K.A. Paschalidis, B. Bouamama, A.B. Salem-fnayou, A.W. Ghorbel, A. Mliki, and K.A. Roubelakis-Angelakis. 2010. Abscisic acid signals reorientation of polyamine metabolism to orchestrate stress responses via the polyamine exodus pathway in grapevine. J. Plant Physiol. 167:519-525.

Xing, S.G., Y.B. Jun, Z.W. Hau, and L.Y. Liang. 2007. Higher accumulation of $\gamma$-aminobutyric acid induced by salt stress through stimulating the activity of diamine oxidases in Glycine max (L.) Merr. Roots. Plant. Physiol. Biochem. 45:560-566.

Xu, R., M. Yamada, and H. Fujiyama. 2013. Lipid peroxidation and antioxidative enzymes of two turfgrass species under salinity stress. Pedosphere 23:213-222.

Yu, J., H. Du, M. Xu, and B. Huang. 2012. Metabolic responses to heat stress under elevated atmospheric $\mathrm{CO}_{2}$ concentration in a coolseason grass species. J. Amer. Soc. Hort. Sci. 137:221-228.

Zaher-Ara, T., N. Boroomand, and M. SadatHosseini. 2016. Physiological and morphological response to drought stress in seedlings of ten citrus. Trees 30:985-993.

Zhou, B., Z. Guo, J. Xing, and B. Huang. 2005. Nitric oxide is involved in abscisic acidinduced antioxidant activities in Stylosanthes guianensis. J. Expt. Bot. 56:3223-3228. 